\title{
A SQUAMOUS EPITHELIOMA, INVOLVING THE FRONTAL AND SUPERIOR MAXILLARY SINUSES IN A MARE. ${ }^{1}$
}

\author{
By Captain J. F. D. Tu'r', M.R.C.V.S., F.R.M.S. \\ (late R.A.V.C. (T.F.), Winchester).
}

THE subject from which this growth was removed was a cart mare, 20 years of age, used for farm work.

The patient had hat a previous attack of nasal gleet, following catarrh, of a few months' duration during 1918, but the gleet did not recur until early in 1919. When tirst seen, early in March, there was a purulent discharge from the near nostril. After some delay the owner consented to trephining of the frontal and maxillary sinuses, this being carried out under the influence of a local anæsthetic (collosol cocaine) on 27th March. No discharge could be obtained from the lower maxillary opening when an irrigation douche was put in at the frontal opening, but one was readily obtained if the douche was inserted in the maxillary opening, through the one in the frontal bone.

On 26th April, under the influence of a general anæsthetic, the frontal sinus was again trephined at the site recommended by Siedamgrotzky, i.e., about one-half to three-quarters of an inch in front (below, if the bead be held with its long axis disposed vertically) of a horizontal line drawn between the two inner angles of the eye, and $1 \frac{1}{4}$ to $1 \frac{1}{2}$ inches from the middle line of the face, and communication between it and that of the nose effected by thrusting a director downwards and inwards at the decpest point, breaking through the thin plate of bone and the mucous membrane covering it, and enlarging the opening so made by excising with a tenotome an oval fragment three-quarters of an inch long and three-eighths of an inch wide. Attention was then directed to the original opening in the superior maxillary sinus, and a pair of throat forceps was inserted in the frontal opening and thrust towards that in the maxillary, and vice versa, until the obstruction which was present, and which appeared to be a small polypus, was removed, and direct connection thereby established.

This, however, was of very short duration, and when seen again after an interval of a week no drainage was obtainable from either of the two openings, and the superior maxillary bone on the near side was bulging.

On the 10th of May the patient was again put under the influence of a general anæsthetic, and the frontal sinus again opened a little below the first opening, and a square piece of bone removed.

It was then observed that the entire simus was completely filled by the growth, which was strongly attached to the bony septum that separated the left and right frontal sinuses. Destruction was advised and carried out, and a post-mortem examiuation made.

\footnotetext{
Recuived May 31, 1919.
} 


\section{Risult of P'ost-mortem Examination.}

The left fiontal sinus was wholly occupied by the growth, which extended right down into the superior maxillary sinus; and the fifth upper molar tooth on this side was pushed out of its socket and was earions, and was easily removed by the finger. Inferiorly, the growth was rapidly forcing its way through the nose and underlying palate.

A portion of the growth was retained for microscopical examination and sent to Professor James Ritchie, who has very kindly examined it and reported as follows:

"The growth shows the structure of a typical squamous epithelioma of a very cellular character. There are numerons early cell nests, with processes of tumour cells (Fig, 1). The bony lamine are separated by

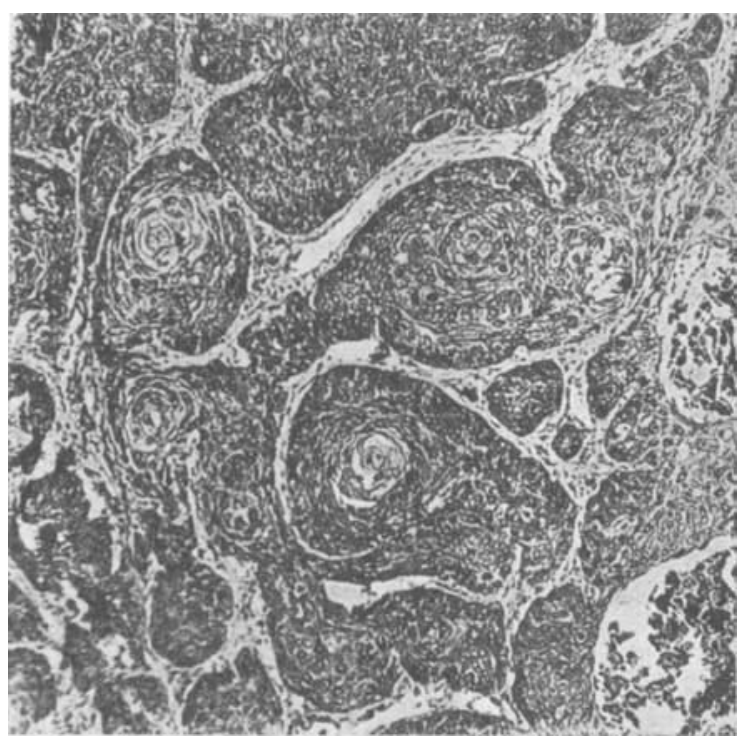

Fig. 1.

a myxomatous and fibrillar connective tissue, which is permeated by tumour cells. Numerous polymorphonuclear cells are present in the surface layers."

It is owing to the comparative rarity of this class of tumour in this region in the horse that the case is placed on record.

\section{REFERENCE.}

1. SuAlie Joxes. . . . . "The Surgical Anatomy of the Horse," 1906, Part 1, p. 106. 